Doi: 10.5212/Uniletras.v.37i2.0008

\title{
AVALIAÇÕES SUBJETIVAS EM CARTAS NOTARIAIS SETECENTISTAS
}

\author{
SUBJECTIVE EVALUATIONS IN EIGHTEENTH \\ CENTURY NOTARIZED LETTERS
}

\author{
Elódia Constantino Roman" \\ Waldiney Corrêa Martins"*
}

Resumo: Dentro dos estudos estilísticos, Martins (1989) propõe três tipos de avaliação nos quais a subjetividade pode se manifestar: a quantitativa, a modalizadora e a apreciativa. Partindo disso, o objetivo deste trabalho é observar as avaliações subjetivas realizadas por modalização, quantificação e apreciação, bem como a anteposição dos adjetivos e o uso do vocativo, que também pode revelar subjetividade. $\mathrm{O}$ corpus de análise compreende quatro Cartas Notariais do século XVIII, do município de Paranaguá, que constam do livro Scripturae na Villa de Pernagoa-Manuscritos setecentistas (2007). Como aporte teórico, além de Martins (1989), temos Lapa (1998) e estudiosos que tratam da história da língua portuguesa, como Câmara Junior (1979) e Castilho (1992), entre outros.

Palavras-chave: Cartas Notariais; Avaliações; Subjetividade

AвSTRACT: Within the stylistic studies, Martins (1989) proposes three kinds of judgment in which subjectivity can be manifested: the quantitative, the "modalizadora" and the appreciative. From that, the objective of this study is to observe the subjective judgment by "modalização", quantification and appreciation, as well as the fronting of the adjectives and the use of the vocative, which can also reveal subjectivity. The analysis corpus comprises four Notarized Letters of the eighteenth century, from Paranaguá City, listed in the book Scripturae na Villa de Pernagoa - Manuscritos setecentistas (2007). As theoretical support, we have Martins (1989), Lapa (1998) and scholars that deal with the story of the Portuguese language, as Câmara Junior (1979) e Castilho (1992), among others.

KEYwORDs: Notarized Letters; Judgments; Subjectivity

\footnotetext{
"Mestrando em Linguagem, Identidade e Subjetividade, pela Universidade Estadual de Ponta Grossa. Área: Teoria e Análise Linguística.walcorrea1@gmail.com

"Doutora em Linguística e Língua Portuguesa pela Universidade Estadual Paulista Júlio de Mesquita Filho, Brasil, Professora Associado da Universidade Estadual de Ponta Grossa, Brasil. ecroman61@yahoo.com.br
} 


\section{INTRODUÇÃO}

Propusemo-nos, no decorrer de nossa pesquisa, a observar os três tipos de avaliação propostos por Martins (1989), nos quais a subjetividade pode se manifestar. Além disso, damos destaque à anteposição dos adjetivos em relação aos substantivos, uma vez que, segundo Lapa (1998), a anteposição sugere um valor subjetivo.

O corpus de análise compreende quatro Cartas Notariais do século XVIII, do município de Paranaguá, que compõem o Livro Scripturae na Vila de Pernagoa - documentos setecentistas (2007). Essas Cartas foram editadas, mantendo seus aspectos originais, ou seja, apresentam ortografia que, muitas vezes, difere da ortografia atual.

Primeiramente, traçamos alguns aspectos da história da língua portuguesa, com o intuito de que o leitor possa entender melhor o contexto sócio-histórico e linguístico em que as referidas Cartas Notariais foram escritas e na sequência partimos para a análise.

\section{A LÍNgua PoRTUguesa No BRAsil}

Do século XVIII, século em que as Cartas Notariais em análise foram escritas, até nossos dias, a língua portuguesa sofreu várias modificações, uma vez que as línguas são dinâmicas e estão constantemente em processo de renovação. Assim, entendemos ser de grande valia mencionar alguns fatos históricos, a fim de situar o leitor no que diz respeito à época em que essas Cartas Notariais foram escritas.

Nesta pesquisa, nosso objetivo não é identificar as mudanças linguísticas, mas, como já mencionado anteriormente, observar o emprego/o uso de elementos linguísticos que permitem alguns tipos de avaliação nos quais a subjetividade pode se manifestar.

De acordo com Câmara Junior (1979), o Brasil foi descoberto pelos portugueses no primeiro ano do séc. XVI. No entanto, entende-se que o movimento de colonização do litoral só começou nos meados desse século. Quando os portugueses chegaram ao Brasil, segundo Castilho (In: ILARI, 1992, p.239), "pouco mais de um milhão de indígenas, distribuídos por cerca de 300 línguas diferentes, povoavam o território".

Os portugueses, segundo Câmara Junior (1979, p.28), aculturaram, "em grande parte, os índios Tupis da costa, que foram os seus guias e aliados na marcha de paulatina penetração da terra”. Além disso, os dialetos que esses indígenas falavam "foram aprendidos pelos brancos, e aí se desenvolveu uma língua geral de intercurso, que era fundamentalmente o dialeto tupinambá”. Dessa forma, o autor entende que "eram duas línguas que coexistiam simultaneamente no mesmo território", ou seja, ocorria uma situação de bilinguismo. Ainda, segundo Câmara Junior (1979, p.29), “a intensificação da imigração portuguesa e o desenvolvimento maior dos valores culturais europeus determinaram [...] a extinção do bilinguismo português e tupi em favor do português".

O autor destaca que, mais tarde, houve o início do tráfico de negros africanos, como escravos, para o Brasil, os quais tiveram de criar uma língua para intercurso, o português crioulo, já que pertenciam às mais variadas nações negras. Castilho (In: ILARI, 
1992) estima que, de 1538 a 1855, 18 milhões de escravos negros foram trazidos para o Brasil.

Portanto, devido à influência de várias línguas, a língua portuguesa incorporou contribuições léxicas indígenas e africanas. No entanto, não destacamos essas influências nos documentos analisados por não ser o objetivo deste ensaio, uma vez que foram escritos seguindo padrões da língua que se prestava à escritura de documentos oficiais naquela época.

\section{Breve histórico de Paranaguá}

Segundo Silva (In: AGUILERA; VASCONCELOS, 2007), os primeiros habitantes do Paraná, Estado situado no sul do Brasil, foram os índios Carijó e Guarani (Tupi) no litoral e os Caingangue (Jê), na região interiorana. A pesquisadora destaca que o interesse português pelas terras onde moravam esses índios se deu em virtude da descoberta do ouro.

O povoamento dos portugueses no Estado do Paraná, de acordo com a autora, começou pelo litoral, na metade do século XVII. O atual município de Paranaguá, portanto, que fica situado na região litorânea do Estado, foi fundado durante a época da exploração das minas de ouro, conforme entende Vasconcelos (In: AGUILERA; VASCONCELOS, 2007).

Dentre algumas datas importantes destacadas por Vasconcelos (In: AGUILERA; VASCONCELOS, 2007) em relação a essa época, citamos as seguintes: foram criadas a Capitania de Nossa Senhora de Paranaguá, pelo Marquês de Cascais, em
08 de março de 1655, e uma Ouvidoria Geral para as Capitanias do Sul, em 1700, ficando o Ouvidor estabelecido em São Paulo. Rafael Pires Pardinho foi nomeado Ouvidor Geral para as Capitanias do Sul, em 1719. Instalouse a Ouvidoria de Paranaguá, em 1724. Foram criadas várias comarcas, em 1812, transferindo-se a sede da Ouvidoria de Paranaguá para a Vila de Curitiba. E, em 1832, com a extinção da Ouvidoria, a Capitania de Paranaguá foi

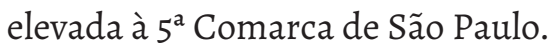

Em se tratando do século XVIII, Vasconcelos (In:AGUILERA; VASCONCELOS, 2007) entende que, com o esgotamento do ouro no Paraná e a descoberta de ouro nas Minas Gerais, houve um esvaziamento populacional nas áreas mineradoras paranaenses.

Com o término da exploração de ouro, a autora destaca o início de uma nova fase econômica em Paranaguá: a agricultura e o tropeirismo (transporte de mercadorias com o uso de animais). Mais tarde, com o aparecimento das ferrovias, tipo de transporte mais moderno, a autora ressalta que o tropeirismo perde sua função, permanecendo apenas em algumas regiões.

Atualmente, Paranaguá é um dos municípios do Paraná que mais se destaca, bem como Curitiba, a capital, segundo Silva (In: AGUILERA; VASCONCELOS, 2007).

É nesse contexto sócio-histórico, conforme destaca Vasconcelos (In: AGUILERA; VASCONCELOS, 2007), que os documentos, aqui analisados, foram escritos.

Traçado esse breve panorama sócio-histórico e linguístico, Silva (2004, p. 44) ressalta que continuam os estudos de documentos do passado, já que são uma fonte de “[...] dados 
confiáveis para estudos histórico-diacrônicos" - como é o caso das Cartas Notariais do século XVIII, que analisamos.

Passamos, na sequência, a tratar das avaliações subjetivas.

\section{As AVALIAÇÕES SUBJETivas}

No que diz respeito aos estudos estilísticos, Martins (1989, p.191) destaca o uso de quantificadores como um dos tipos de avaliação, nos quais a subjetividade pode se manifestar. Segundo a autora,

quando se diz que alguém pesa 80 quilos, podemos achar que seja um peso normal ou excessivo, dependendo de outras características da pessoa. Se for uma adolescente de $1,60 \mathrm{~m}$ de altura, então a avaliação poderá ser acompanhada de desaprovação. Quando nos informam que um livro custa $\mathrm{NCz} \$$ 10,00(sic), podemos achá-lo caro ou barato, em relação à qualidade do livro, ao preço dos livros em geral, ou ao nosso poder aquisitivo. Mais subjetiva, por imprecisa, é a avaliação quantitativa com indefinidos como muito, pouco, algum, etc.

Portanto, o uso de quantificadores pode ensejar uma avaliação por parte de um sujeito. Outro tipo de avaliação em que a subjetividade pode se manifestar, segundo Martins (1989), é a avaliação modalizadora. Para a autora, neste tipo de avaliação, o locutor revela se considera o fato a que se refere como verdadeiro (utilizando-se, por exemplo, de expressões como sem dúvida, realmente, indiscutivelmente) ou falso.
Além disso, a autora entende que, se o enunciado é objeto de citação, o locutor pode se utilizar de alguns verbos como afirmar e garantir, conforme podemos observar na análise o uso do verbo certificar.

O último tipo de avaliação citado por Martins (1989) é a axiológica ou apreciativa. Para a autora, esse tipo de avaliação é a do valor moral ou estético, prendendo-se aos binômios, como útil/inútil, bonito/feio.

A respeito do adjetivo, Lapa (1998, p.126) entende que a posição do adjetivo qualificativo pode demonstrar uma escolha avaliativa por parte do produtor do texto. $\mathrm{O}$ autor destaca que, muitas línguas, como o inglês e o alemão, têm sempre o adjetivo antes do substantivo. Por sua vez, línguas, como o português e o espanhol, "admitem liberdades que dão a quem fala e escreve riquíssimas possibilidades de expressão".

$O$ autor considera que, quando o adjetivo está depois do substantivo, tende a conservar o valor próprio, objetivo. E, quando está antes, "tende a embrandecer-se, adquirindo matização afetiva" (1998, p.127).

Da mesma forma, Martins (1989) entende que se coloca o adjetivo posposto ao substantivo quando se quer particularizá-lo, distingui-lo de outros. E coloca-se o adjetivo anteposto ao substantivo quando se quer exprimir um valor apreciativo. $\mathrm{O}$ emprego do adjetivo anteposto, portanto, pode sugerir um valor subjetivo, expressivo.

Assim como da posição do adjetivo, Martins (1989, p.167) trata da posição do advérbio. Segundo ela, "os advérbios intensificadores, que se incluem num sintagma nominal, modificando adjetivo ou particípio 
[...], são normalmente antepostos" e podem indicar o julgamento do falante a respeito do fato que enuncia.

Além disso, Martins (1989, p.214) trata da colocação do vocativo. Segundo a autora, ele permite várias colocações (início, meio e fim da frase) e é utilizado com função apelativa, isto é, chama um interlocutor, "provocando-lhe a atenção, e, ao mesmo tempo, renovando o contato com ele". A autora acrescenta que o vocativo também é afetivo, "pois revela o sentimento do falante em relação ao interlocutor, podendo assumir tonalidades várias, que vão da ternura à rispidez".

Finalmente, Martins (1989, p.192) destaca que o falante pode transparecer sua emoção através do léxico ou de determinadas construções e figuras, o que caracteriza a subjetividade afetiva. Passamos, a seguir, à análise do corpus.

\section{ANÁLISE do CoRpus}

Neste momento, apresentamos a análise de quatro (4) Cartas Notariais. Revitalizamos que nosso objetivo foi observar as avaliações subjetivas realizadas por modalização, quantificação e apreciação, bem como pelas anteposições dos adjetivos, já que, segundo Lapa (1998), a anteposição do adjetivo pode sugerir um valor subjetivo.

Para nossa análise, nos baseamos, portanto, em Lapa (1998) e Martins (1989), que discorre acerca do advérbio intensificador, do vocativo e das avaliações quantitativa, modalizadora e axiológica.

O primeiro documento a que fazemos menção é o de número 17, o qual trata de um "comunicado da satisfação pela notícia da visita do Governador e a esperança de melhoras ao povo de Paranaguá com essa visita", conforme o assunto/resumo contido na ficha catalográfica que antecede o documento. É datado de 23 de agosto de $1732 \mathrm{e}$ tem, como autores, João Teixeira Marinho, João da Veiga, Francisco Luís Matoso e Pedro Rodrigues.

$$
\text { [[23-Agosto-1732]] }
$$

\section{EXCELENTISSIMo SENHOR}

No supremo de nossas cabeças recebemos, e collo camos aboa nova de que fomos partesipantes da chegada e vinda de Vossa Excelencia a esta Capitania aSuceder ao Governador que acabou, Antonio da Sylva Cal deyra Pimentel em cuja sucessaõ esperamos boa creaçaõ, e aumento do bem commum deste Povo, que sempre se empregou zellozo no serviço de Sua Magestade que Deus guarde

Ficamos de acordo naõ. só observarmos, 
As ordens que por VossaExcelencia nos for enviado, como tã= bem de rogar a Deus prospere a Saude aVossa Excelencia para sua ma?or gloria, eserviços a Sua magestade que Deus guarde Os longes desta villa a essa cidade discul=????? pará afalta que nesta Vossa Excelencia verá pois o naõ conhe cemos senaõ senaõ para muy humildes, e sem= pré leaes nos empregarmos no servisso devossa Excelencia que Deus guarde por muitos annos. Pernagoa em Ca mera 23 de Agosto de $\underline{1732}$

De Vossa Excelencia

\section{Os mais humildes, eLeais subditos}

\section{Łoão Teixeira Marinho \oão Daueigua \\ Francisco Luis Matoso $\underline{\text { Pedro Roiz }}$}

Destacamos o uso do vocativo "Excelentissimo Senhor" e do adjetivo anteposto em "boacreaçaõ", que podem sugerir um valor subjetivo, por parte do escriba, conforme postulações de Lapa (1998). Além disso, negritamos o adjetivo "ma?or" anteposto aos substantivos "gloria, eserviços", uma vez que pode também sugerir um valor subjetivo, por parte de quem redigiu a Carta.

Observamos o adjetivo "humildes" antecedido do intensificador "muy", bem como "sempre" antecedido de "leaes", demonstrando o respeito à autoridade a que estão se dirigindo, através da escrita. Qualidades estas que os autores da Carta se auto-atribuem.

Como fechamento, os autores da Carta de $n^{\circ} 17$ se consideram "Os mais humildes, eLeais subditos" do governador ("Vossa Excelencia”). Observamos o uso do intensificador mais anteposto ao adjetivo humildes e, ainda, mais um qualificador, leais, como que estando à disposição "de Vossa Excelência” e com lealdade ao governador.
Na sequência, analisamos o documento $n^{\circ} 21$, cujo assunto/resumo é: "a Câmara de Paranaguá juntamente com o Ouvidor Antonio dos Santos Soares arbitram em quatro réis o valor de propinas a ser pago ao secretário”. A Carta é datada de 30 de dezembro de 1732 e tem, como autores, João Teixeira Marinho, João da Veiga da Siqueira, Antonio Luís Matoso e Pedro Rois. 
[[30-Dez-]] [[Paranaguá]]

\section{Excelentissimo Senhor}

[[1732]]

Aos $\underline{17}$ de Outubro recebemos eveneramos as

de vossaExcelencia de $\underline{12}$ deSeptembro, ecomella o bando

que vossaExcelencia foi servido mandar sepublicasse o que logo

foi satisfeito como da inclusa certidam vossa Excelencia verâ.

Attendido por nõs ade VossaExcelencia nos jun tamos

com oDoutor Antonio dos Santos Soares, Ouvidor

destacomarca; para effeito de se arbitrar o quanto

poderia dar estaCamera de propinas ao Secretario

achou o dito Ouvidor; attendido por elle, e por nos

as pocibillidades destaCamera; arbitrar 4 reis -

queconsta dacertidam junta, que va? Com o theor

do termo do arbitramento a qual fica esta aordem

de vossaExcelencia que detriminará se selhe hade reme

ter ou entregar cá aquém ofassa.

Tambem vemos o Paternal afecto com

que VossaExcelencia seofferece attender aos particulares

deste senado, e reprezsentallos a realgrandeza;

no que vive este Povo grã tuoza mente confiado, e

assim nôs ficamos rogando a Deos prospere a

vida esaude avossaExcelencia para amparo desta

cappitania Deos guarde avossaExcelencia muitos annos Parnagua

30 de Dezembro de 1732

De vossaExcelencia

Excelentissimo Senhor Conde das Sarzedas

os mais humildes subditos

Loaõ Teixeira Marinho Loaõ Da ueiga Da Siqueira

Antonio Luis Matozo $\quad \underline{\text { Pedro Rois }}$

Primeiramente, destacamos o vocativo "Excelentissimo Senhor" e o uso do adjetivo anteposto ao substantivo, nos casos "Paternal afecto" e "realgrandeza", podendo sugerir uma avaliação por parte dos autores, isto é, um valor subjetivo. "Paternal" como alguém que deseja o melhor para seus "filhos", o povo da vila de Paranaguá. 
Destacamos, também, a anteposição do adjetivo "humildes" ao item lexical "subditos", bem como o uso do intensificador "mais", podendo sugerir um valor subjetivo, conforme postulações de Martins (1989). "Os mais humildes subditos” faz remissão ao que é mencionado posteriormente, isto é, os nomes dos autores da Carta.

Passamos, agora, a analisar o documento de número 23, o qual é datado de 12 de abril de 1732. Nele, "oficiais da Câmara de Paranaguá informam e justificam ao Governador o aumento do ordenado do escrivão", conforme o próprio resumo/assunto contido na ficha catalográfica que antecede o documento. Os autores são (vas da) Silva, Pedro de Sousa Pereira, João Duarte, Valentim (Reis) de Almeida e (Antonio) Igínio.

\section{[[12 Abril 1735]] Excelentissimo senhor $\quad 1^{\text {a }}$ Via [[Paranaguá]]}

Mandanos VossaExcelencia que informemos sobre o contheudo daordem junta cuja copia foi servido remeternos, $\mathrm{ad}=$ junto com os dous cappitulos de correição que nesta Villa fes em o anno de 1733 o ouvidor da Comarqua Antonio dos Santos Soares; em quanto ao particular do or= denado ao escrivaõ nesta Camara aoque dando execuçaõ.

Informamos avossaExcelencia que por requerimento do pro= curador doconcelho que esta no dito ano, feito em acto decorreiçaõ edetodos os officiaes daCamara Se requereo que ao escrivaõ, visto $\mathrm{o}$ lemitado ordena= do que tinha de dez mil reis só mente tendo excessivo trabalho, e escrita que nada levava outro emullumento sepudece pagar mais seis mil reis que por tudo $\mathrm{fa}=$ riaõ dezaseis, ao que deferio odito corregedor que se pagacem athe ordem deMagestade queDeus guarde o levar abemSendo Servido.

Ehé certo queofundamento quetiveraõ os ditos officiaes da Camara para o referido requerimento foi com verdadeira cau= za, e motivo oque certeficamos, e informamos, sa= tisfazendo a ordem junta, ede vossa Excelencia que Deus guarde muitos annos Pernaguá $\underline{2}$ deAbril de 1735

Os officiaes daCamara da Villa dePernaguã (vas da) Silva Pedro de Sousa Pereira Loão Duarte Valentim (Reiz) de Almeida (Antonio) Igínjo 
Primeiramente, destacamos o uso do vocativo "Excelentissimo senhor", bem como a anteposição do adjetivo em "lemitado ordenado". Com isso, entendemos, conforme postulações de Lapa (1998), que a anteposição do adjetivo pode trazer uma marca de subjetividade, uma vez que os autores da Carta tentam ressaltar, segundo suas intenções, que o escrivão recebia pouco.

Observamos o que Martins (1989, p.191) entende por avaliação quantitativa, isto é, os autores da carta novamente consideram pouco o valor pago ao escrivão, o que é quantificado pelo advérbio "somente".

Negritamos, também, a anteposição de "excessivo" à expressão nominal "trabalho, e escrita". Pode se tratar de um adjetivo intensificador e sugerir um valor subjetivo. "Excessivo trabalho e escrita" são argumentos para justificar o aumento do salário do escrivão.

Destacamos, também, a anteposição do adjetivo "verdadeira" aos substantivos "cauza e motivo". Com isso, também entendemos tratar-se de uma avaliação modalizadora.

Os autores se utilizam do "certeficamos”, uma vez que o enunciado é objeto de citação. Há uma asseveração seguida da informação. Com isso, revelam que consideram o fato a que se referem como verdadeiro, caracterizando uma avaliação modalizadora em que a subjetividade pode se manifestar, conforme postulações de Martins (1989). Em se tratando do verbo, também destacamos o uso do verbo "informar", dando ciência à autoridade de todos os fatos acontecidos, espécie de "fidelidade" para com a autoridade.

Passamos, agora, a analisar o documento de número 20. Nele, o "escrivão Gaspar Gonçalves de Morais certifica em Câmara o Termo de Vereança sobre o pagamento de propina ao Secretário e sobre as despesas com a construção da cadeia”, conforme o resumo contido no próprio documento. É datado de 29 de dezembro de 1732 e tem, como autor, Gaspar Gonçalves de Morais.

[[19-Dez.-1732]]

Gaspar Gonçalvez deMorais escrivaõ da Camera edo publico orfons e mais a

Nexos etcetera Certifico que no Livro que serve Das vereanças neste senado a folha 222 se Acha hu termo do theor seguinte // Termo de vereança em que se arbitra propina do Secretario de Concelho // Aos vinta nove dias do mes de Dezembro de mil esete centos etrin ta edous annos nesta Villa de nossa Senho ra do Rozairo capitania dePernagua nos passos do concelho estando em camera os offeciaes della onde seachava prezente o 
ouvidor geral ecorregedor desta comarca

o Doutor ouvidor digo Doutor Antonio dos Santos

Soares eo Juiz ordinário Joaõ Teixera Marinho

sendo lhes pelo dito Doutor ouvidor geral aordem

que tem deSua Magestade que Deus guarde queseacha

Registada no livro desta ca mera pela qual

o dito senhor manda a elle dito ouvidor ad junto com os mais offeciaes desta ca mera ar bitracem oque deve pagar esta ca mera depro pina ao Secretario doConcelho, e com ciderada apocibillidade della e rendimentos que tem emcadahu a nno que naõ hé mais que os sucidios das Bebidas que entraõ naterra ealguns foros do Rocio o quetudo por hu anno renderá pou co mais de duzentos mil reis os quais estão aplicados para aobra daCadeya que seanda formando cuja obra hade emportar mais de quatorze mil cruzados depois deacabada, lhe naõ fica para outra dis peza rendimento algum, arbitraraõ com tudo emcomprimento da ordem deSua Magestade pa

pagace estacamera aquantia de quatro milreis cada anno, esendo queos rendi mentos desta câmera forem a mais e sea cabe aobra se haja defazer novo arbitramento deque tudo mandaraõ fazer este termo que asignaraõ com o dito Dou tor ouvidorgeral eu Gaspar Gonçalvez de Mo rais escrivaõ doSenado que escrevi // Soa res // Marinho // Siqueira // de Almeida // Matozo // Rois // e não se continha mais no dito termo que aqui o expre sey nesta certidão extrahido do dito livro ao 
qual me reporto e vay na verdade emfé de meo officio Paranaguá 29 de Dezembro de 1732

Gaspar Gonçalvez de Morais

Negritamos, acima, o verbo "certificar", que o autor utiliza a fim de passar veracidade ao que vai dizer na sequência, podendo sugerir um valor subjetivo. Além disso - considerando a ordem inversa dos componentes frasais - à Câmara, não fica "rendimento algum" para outra despesa. "Rendimento algum", destacado acima, entendemos tratar-se de uma avaliação quantitativa, conforme postulações de Martins (1989).

\section{Algumas considerações}

Tendo em vista que, segundo Lapa, em um texto, o uso do adjetivo anteposto ao substantivo sugere um valor avaliativo por parte de seu produtor, nas Cartas em análise, observamos como essa subjetividade se apresenta nos adjetivos.

Observamos algumas avaliações subjetivas com base em Martins (1989), bem como a construção de sintagmas nominais por meio de adjetivo anteposto ao substantivo, como em "Paternal afecto". Neste caso, por exemplo, entendemos tratar-se de uma avaliação dos autores para o governador, devido ao tratamento atencioso com o povo da vila. Isso também ocorre no fechamento, sendo que, além de adjetivos, há o uso de intensificadores, mostrando o respeito pela autoridade a que os autores se referem.

Feitas essas considerações, concluímos que a Carta Notarial é um documento oficial, que requer uma forma padronizada e uma linguagem formal, mas que, também, pode revelar marcas de subjetividade. Afinal, "se a linguagem é sempre produzida por um falante que sente a necessidade, a conveniência, o desejo ou o prazer de dizer qualquer coisa, a linguagem é sempre subjetiva" (MARTINS, 1989, p.190).

\section{REFERÊNCIAS}

CÂMARA JUNIOR, J. M. História e estrutura da língua portuguesa. 2. ed. Rio de Janeiro: Padrão, 1979.

CAStilho, A. T. de. O Português do Brasil. In: ILARI, R. Linguística românica. São Paulo: Ática, 1992.

LAPA, M. R. Estilística da língua portuguesa. 4. ed. São Paulo: Martins Fontes, 1998.

MARTINS, N. S.'A. Introdução à estilística: a expressividade na língua portuguesa. São Paulo: T. A. Queiroz: Editora da Universidade de São Paulo, 1989.

SILVA, R. V. M. e. Ensaios para uma sóciohistória do português brasileiro. São Paulo: Parábola Editorial, 2004.

SILVA, E. B. da. Breve histórico do Paraná. In: VASCONCELOS, Celciane Alves. Breve histórico de Paranaguá. In: VASCONCELOS, Celciane Alves.; AGUILERA, V. de A. (Orgs.). Scripturae na Vila de Pernagoa: documentos setecentistas. Londrina: Universidade Estadual de Londrina, 2007. 
VASCONCELOS, C. A. Breve histórico de Paranaguá. In: ; AGUILERA, V. de A. (Orgs.). Scripturae na Vila de Pernagoa: documentos setecentistas. Londrina: Universidade Estadual de Londrina, 2007. ; AGUILERA, V. de A. (Orgs.). Scripturae na Vila de Pernagoa: documentos setecentistas. Londrina: Universidade Estadual de Londrina, 2007.

Recebido para publicação em 22 out. 2015.

Aceito para publicação em 27 abril 2016. 